\title{
Water Quality Monitoring based on Small Satellite Technology
}

\author{
N. Gallah ${ }^{1}$, O. b. Bahri ${ }^{1}$, N. Lazreg ${ }^{1}$, A. Chaouch ${ }^{1}$ \\ ${ }^{1}$ Microelectronic and Instrumentation Lab \\ ${ }^{1}$ Faculty of sciences, University of Monastir \\ Monastir, Tunisia
}

\begin{abstract}
In order to improve the routine of water quality monitoring and reduce the risk of accidental or deliberate contaminations, this paper presents the development of in-situ water quality monitoring and analysis system based on small satellite technology. A space mission design and analysis was performed in this work. The system consists of three segments; space segment including a constellation of nano-satellites, ground segment entailing the ground station and user-segment containing the in-situ water quality sensors. The authors studied the orbit characteristics and the number of nano-satellites required to cover the Middle East and North Africa (MENA) which presents the most water scarce region of the world. Thus, 9 nano-satellites distributed in 5 low earth orbits $(600 \mathrm{~km})$ are needed to cover MENA region continuously for about all the day. Data collected by various sensors such as $\mathrm{pH}$ and temperature are sent through Software Defined Radio (SDR) module which is responsible for the satellite communication.
\end{abstract}

Keywords-space mission; nanosatellite; SDR; autonomous; on-line water monitoring

\section{INTRODUCTION}

According to the Intergovernmental Panel on Climate Change (IPCC, 2016), the Middle East and North Africa (MENA) region is projected to experience an increase of $3^{\circ} \mathrm{C}$ to $5^{\circ} \mathrm{C}$ in mean temperature and $20 \%$ decline in precipitation by the end of this century. The consequence of this climate change on water run-off is projected to drop by $20 \%$ to $30 \%$ in this region by 2050. In MENA region, further 83 million persons (about $27 \%$ of population) need to be supplied with safe water. Clearly, the implementation of carefully real-time and remotely water-quality monitoring systems is becoming necessary for large water distribution networks [1], to prevent accidental or deliberate contamination [2]. It is undeniable that water is an important element of economy and a vital resource for the world.

As an example of interest, the World Bank, USAID and NASA are collaborated for establishing a scientific program based on satellite earth observations (images, maps...) for water management in this region (fig. 1a). This initiative was launched in October 2011 and it is scheduled by the end of 2015 [3]. In addition, European Space Agency (ESA) launched satellites aiming for earth observation with the capability of inland water quality monitoring (fig. 1b)

\author{
Kamel Besbes ${ }^{1,2}$ \\ ${ }^{2}$ Center for Research on Microelectronics and \\ Nanotechnology, CRMN \\ Sousse, Tunisia
}

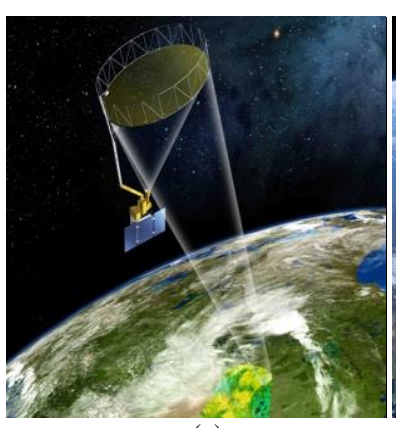

(a)

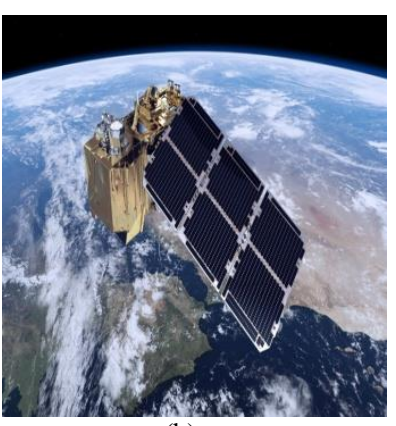

(b)
Fig. 1. Satellite earth observation. (a) NASA project (Courtesy of NASA ${ }^{l}$ ). (b) ESA project (image by ESA/ATG medialab ${ }^{2}$ )

However, the satellite earth observation systems present always gaps. The earth observation methods used for water quality monitoring are based on sensors resolution. Indeed, almost of this projects focus on ocean monitoring. The spatial resolution not suitable for lakes and rivers monitoring (water quality parameters measurement) that are need more accuracy. It is based on spectral response, thermal and scattering reflexion from water or by combination of spectral and microwave techniques. These methods need accuracy improvement in order to effectively fill observational gaps such as the determination of water quality parameters based on texture analysis method [4]. In addition, the launch of a satellite for earth observation purpose requires big budgets when good resolution and accuracy needed. The best way to improve the water quality monitoring is by combining data between the satellite earth observations and the in-situ measurement system.

The traditional method of in-situ measurement is based on water sampling which could become very expensive. It is in addition slow and unreliable due to the analysis time consuming in laboratory. Indeed, water-quality monitoring must be continuous and alerts should be sent whenever it's necessary. It becomes possible to properly register the annual evolution but also to foresee risks and to plan new development models. The number of scientific research and development systems is extremely large in this area. Thus, several researches focused on the development of in-situ waterquality measurement systems avoiding the traditional method.

\footnotetext{
${ }^{1}$ https://www.nasa.gov/smap

${ }^{2}$ http://www.odermatt-brockmann.ch/sponge/
} 
The development of environmental sensing technology offers a promising application for future evolution [5], with different data sharing methods such as, Wireless Local Area Network (WLAN) [6], Wireless Sensor Network (WSN) [7-12], including different communication technologies such as Zigbee transmission method [13-16], or GPRS network [17-19].

These communication methods present a limitation to monitor our water resources on a large scale and in area without infrastructure, especially in developing countries. Nevertheless, Transboundary water issues will continue to plague the MENA region and others in terms of sharing data for better management of water resources. Indeed, the fast developments of the small satellite technology open a new era in this field. The nano-satellite technology can offer to the region and others an important contribution both to the autonomy of the management and sharing data related to water quality [20]. Furthermore, it can provide the international cooperation in the field of environment monitoring of our planet.

This work is one part of the small satellite mission for water telemetry and control. The entire mission consists of the cubesat constellation, the ground station and the in-situ waterquality sensor system. The main objective of this paper is the development of the in-situ water-quality measurement system reducing the mission cost. In this regard, a microcontroller board is used at node, which is a low cost device intentionally made as easy to program. Two important water quality parameters were measured: $\mathrm{pH}$ and temperature. The system developed in this work is reliable for adding other water quality sensors. Indeed, a wireless sensor network is proposed made up of set of sensor nodes. The topology and the techniques used in this network provide easy deployment of the nodes anywhere in the distribution water system without any particular limitation. The microcontroller unit (MCU) collects the information and sends them to the Software Defined Radio (SDR) module which is responsible for the communication with the nano-satellites such as HumSat constellation [21]. The SDR module adapts the signal received from the MCU to the appropriate protocol of communication and transfers it to the nano-satellite constellation. This network architecture is proposed in order to reduce the conflict and improve the communication between the sensor network and the nanosatellites. A prototype system was developed and tested at real water resources by measuring the $\mathrm{pH}$ and the temperature parameters continuously.

\section{ENTIRE MISSION DESCRIPTION}

Figure 2 illustrates the entire mission architecture. It consists of three main segments; the space segment, the ground and user segments. Indeed, water-quality monitoring has a promising application for the nano-satellite technology. Thus, the objective of the proposed system is to monitor water quality remotely and in a real-time. Therefore, the nanosatellite technology was considered as it is a better solution for wireless water-quality monitoring in zone without infrastructure. In addition, it facilitates sharing data regarding the transboundary water issues.

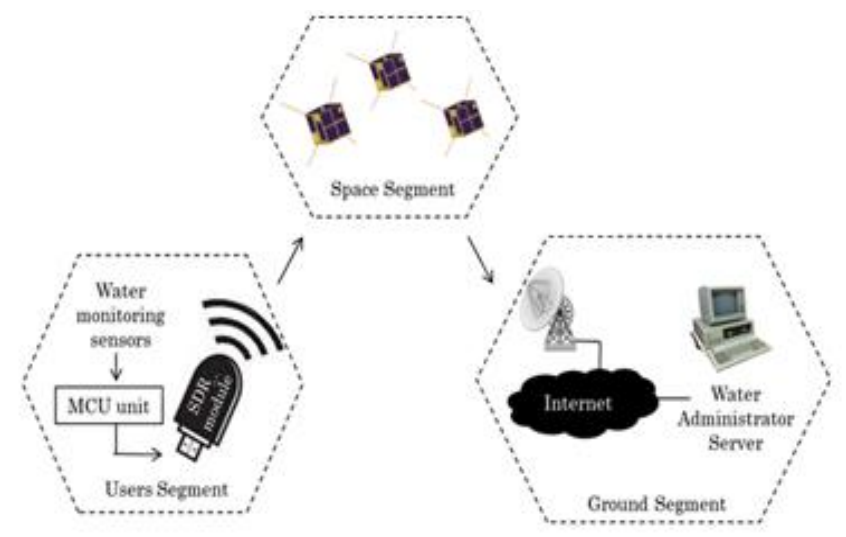

Fig. 2. Entire mission architecture

Accordingly, the integration of the small satellite technology in the routine of water-quality monitoring and management is very interesting. This work is one part of the general project which consists of three segments: space segment including a constellation of nano-satellites offered by the International University of space projects, ground segment entailing the ground stations included in radio amateur University Network such as GENSO [22] and user-segment which contains the in-situ multi-parameter water-quality sensors. The main contribution of this work is the development of a low-cost water-quality system. Thus, an MCU board with an Atmel microcontroller was used at node for transmitting data collected by sensors. The choice of the SDR technology is based on the entire project and the integration of the small satellite technology for water quality monitoring. A wireless sensor network which is based on USB-UHF Bridge was proposed based on SDR module capabilities. This bridge is a wireless communication device where the transmitter and receiver operations are changed or modified by software alone without making any (physical) changes to the hardware, which can reduce costs, improves reliability and allows to process real-time high bandwidth and simultaneously performs the decoding multiple emissions being in this band [23].

The communication scenario is listed below:

- In-situ water quality sensors collect the water parameters,

- The microcontroller board acquires these parameters and sends them through the SDR module,

- The USB-UHF Bridge receives data, adapts to the appropriate communication protocol and sends them to the nanosatellite constellation.

Finally, the data received from the nanosatellite through the ground station will be distributed through internet.

\section{NANO-SATELLITE CONSTELLATION}

The Middle East and North Africa is the region with the most water stress in the world. Therefore, the coverage of MENA region along about all the day was studied. In fact, one nano-satellite distributed in a low orbit, has coverage of 
discontinuity for a day. Furthermore, it provides a short access unlike a satellite at high altitude. These consequences require many satellites in Low Earth Orbit (LEO) to provide continuous coverage of a specific area.

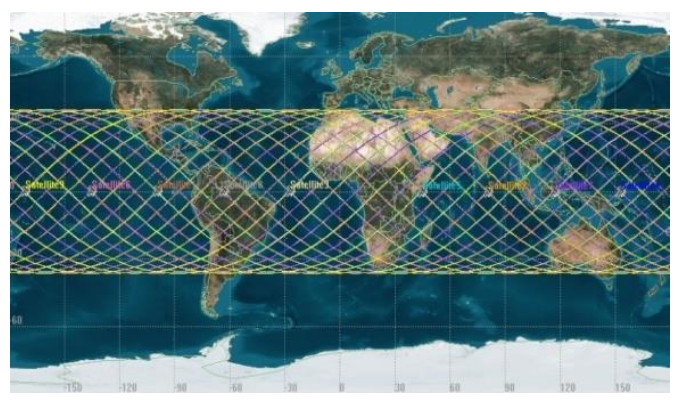

Fig. 3. Coverage of nano satellites constellation

TABLE I. ORBIT PARAMETERS

\begin{tabular}{|l|l|l|l|l|l|l|l|l|l|}
\hline & $\begin{array}{l}\text { Sat- } \\
\mathbf{1}\end{array}$ & $\begin{array}{l}\text { Sat- } \\
\mathbf{2}\end{array}$ & $\begin{array}{l}\text { Sat- } \\
\mathbf{3}\end{array}$ & $\begin{array}{l}\text { Sat- } \\
\mathbf{4}\end{array}$ & $\begin{array}{l}\text { Sat- } \\
\mathbf{5}\end{array}$ & $\begin{array}{l}\text { Sat- } \\
\mathbf{6}\end{array}$ & $\begin{array}{l}\text { Sat- } \\
\mathbf{7}\end{array}$ & $\begin{array}{l}\text { Sat- } \\
\mathbf{8}\end{array}$ & $\begin{array}{l}\text { Sat- } \\
\mathbf{9}\end{array}$ \\
\hline $\begin{array}{l}\mathbf{a} \\
(\mathbf{K m})\end{array}$ & 600 & 600 & 600 & 600 & 600 & 600 & 600 & 600 & 600 \\
\hline $\mathbf{e}$ & 0 & 0 & 0 & 0 & 0 & 0 & 0 & 0 & 0 \\
\hline $\mathbf{I}\left(^{\circ}\right)$ & 36 & 36 & 36 & 36 & 36 & 36 & 36 & 36 & 36 \\
\hline $\mathbf{\Omega}\left(^{(}\right)$ & 0 & 0 & 72 & 72 & 144 & 144 & 216 & 216 & 288 \\
\hline TA $\left(^{\circ}\right)$ & 0 & 180 & 0 & 180 & 0 & 180 & 0 & 180 & 0 \\
\hline
\end{tabular}

In this part, the number of nano-satellites necessary to cover MENA region in a low orbit was investigated. Following Walker constellation architecture, 9 nano-satellites were chosen to accomplish this mission, which are distributed in 5 orbits as shown in table 1 . With this approach, the MENA region can be continuously covered for about all the day as indicated in Fig.3 [24].

\section{GROUND SEGMENT}

The ground segment consists of a ground station connected with the water administrator server which encompasses a network of water monitoring service.

The space-ground interface based on UHF band. The nano satellites constellation uses the UHF band for downlink with $9600 \mathrm{bps}$ at frequency of $437 \mathrm{MHz}$. After being received across the ground station, the data are distributed through Internet (fig. 2). The VHF band was proposed for the uplink commands with $9600 \mathrm{bps}$ at frequency of $145 \mathrm{MHz}$.

\section{USER SEGMENT}

Actually, there are several commercial multi-parameter sondes for water quality parameters measurement. These industrial instruments with high accuracy are very expensive, however, for the detection of water quality changes in water distribution system a less accurate instrument is enough. In this work, a simple cheap sensors system was chosen. It is a block made up two sensors. The measured variables are: temperature (k type thermocouple) and $\mathrm{pH}$ (combined electrode, KCL 3M electrolyte).

\section{A. Hardware system architecture}

The designed system is used to develop an application for real-time and remote water-quality monitoring in large volume water samples. In this paper, we focused on the user-segment. Figure 4 shows the bloc diagram of the segment. A microcontroller board was used at node to process sensor data, while the SDR module was used to send sensors information to the PC. The data was transmitted and received through the UHF band using two SDR modules. The first one was integrated with the user-segment as a transmitter, while the second one was integrated with a PC as a receiver, in order to test the proposed communication architecture based on a bridge type SDR module. Two commercial water-quality sensors were used to measure the $\mathrm{pH}$ and temperature parameters. The microcontroller board used is a tool for making small computers that can sense and control more things of materials as your desktop. It is a programmed electronic open-source platform that is based on Atmega328 microcontroller (AVR family). It is used at nodes which has 14 digital input/output pins, 6 analog inputs, $16 \mathrm{MHz}$ crystal oscillator, a power jack, an ICSP header and a reset button. The features of this controller are $5 \mathrm{~V}$ operating voltage, flash memory of $32 \mathrm{~KB}$, SRAM of $2 \mathrm{~KB}$, EEPROM of $1 \mathrm{~KB}$. In addition, this board support UART, USB, SPI, and I2C communications. In this project, an SDR module is used to create a connection between the microcontroller board and a PC. The MCU receives sensors data collected by the waterquality sensors then sends them to the computer via UHF through the SDR modules. Accordingly, a software program was developed in order to acquire sensor data, convert to $\mathrm{pH}$ and temperature values and send them continuously.

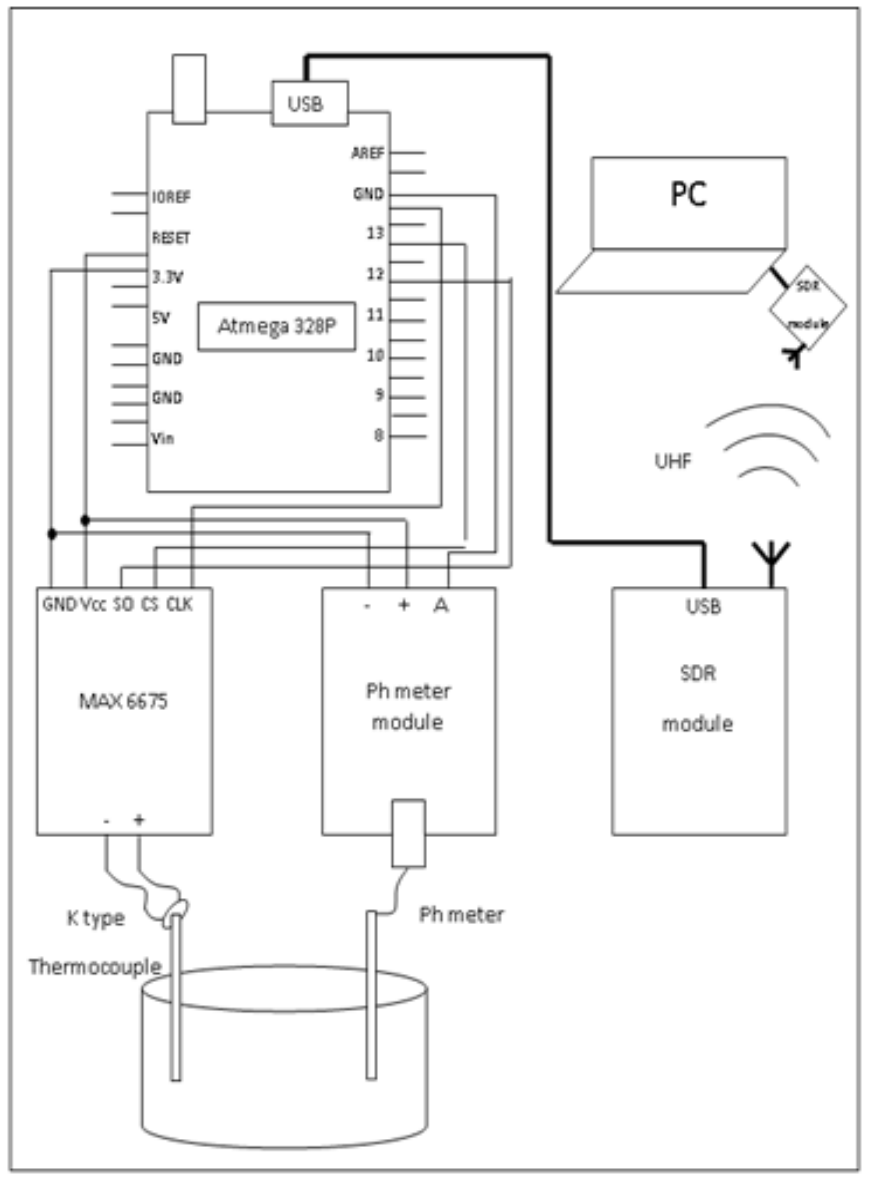

Fig. 4. Hardware system architecture 


\section{B. Temperature sensor}

A K-type thermocouple is used to measure temperature. It's inexpensive, accurate, reliable and has a wide temperature range $\left(-270-1260^{\circ} \mathrm{C}\right)$. The $\mathrm{K}$-type thermocouple has an almost linear part between 0 and $1000^{\circ} \mathrm{C}$ with a see beck coefficient fluctuating around $40 \Delta \mathrm{V} /{ }^{\circ} \mathrm{C}$. In our application, we focused only on the range of $0-100^{\circ} \mathrm{C}$. The temperature interfacing circuit is shown in Fig. 5. The output voltage $(\mathrm{mV})$ measured by the thermocouple in $0-100^{\circ} \mathrm{C}$ range is converted into $0-5 \mathrm{~V}$ range. The cold junction compensation is affected by the MAX6675. Figure 6 presents the characteristic curve of temperature.

\section{C. pH sensor}

High accuracy $\mathrm{pH}$ electrode is used as a $\mathrm{pH}$ sensor. It includes a measuring electrode which measures the potential related directly to the hydrogen ion concentration and a reference electrode which provides a stable potential to be compared to the measured electrode. The transfer function of the $\mathrm{pH}$ sensor is presented in Equation 1.

$$
p H(x)=p H(s)+\frac{\left(E_{S}-E_{X}\right) F}{R T \ln (10)}
$$

where $\mathrm{pH}(\mathrm{x})$ is water solution's $\mathrm{pH}, \mathrm{pH}(\mathrm{s})=7$, is the $\mathrm{pH}$ of standard solution, ES is the electric potential at reference, EX is the electric potential at $\mathrm{pH}$ measuring, $\mathrm{F}=9.6485309 * 104$ $\mathrm{Cmol}^{-1}$, is the Faraday constant, $\mathrm{R}=8.3145 \mathrm{~J} \mathrm{~K}^{-1} \mathrm{~mol}^{-1}$, is the Universal gas constant and $\mathrm{T}$ is the temperature in Kelvin. The theoretical output is approximately $59.16 \mathrm{mV} / \mathrm{pH}$ at $25^{\circ} \mathrm{C}$. Temperature affects the output voltage, thus it is required to compensate. The $\mathrm{pH}$ sensor used is the $\mathrm{pH}$ probe E201. This electrode operates in the full $\mathrm{pH}$ range from 0 to 14 and operates in the temperature range of $0^{\circ}$ to $60^{\circ} \mathrm{C}$. The sensor is terminated with BNC connector. Thus an adaptor was used to convert $\mathrm{BNC}$ to analog voltage to be acquired by the MCU pin.

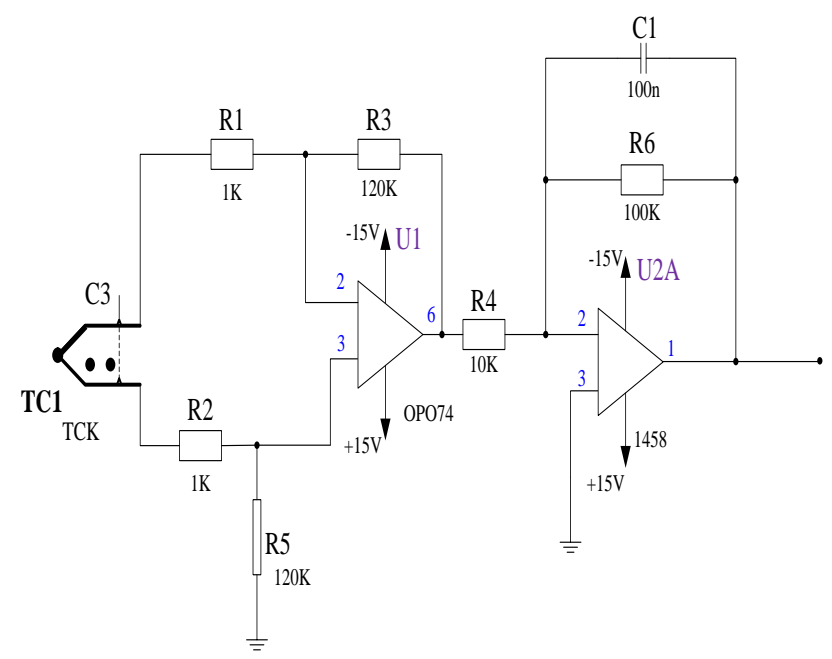

Fig. 5. Temperature interfacing circuit

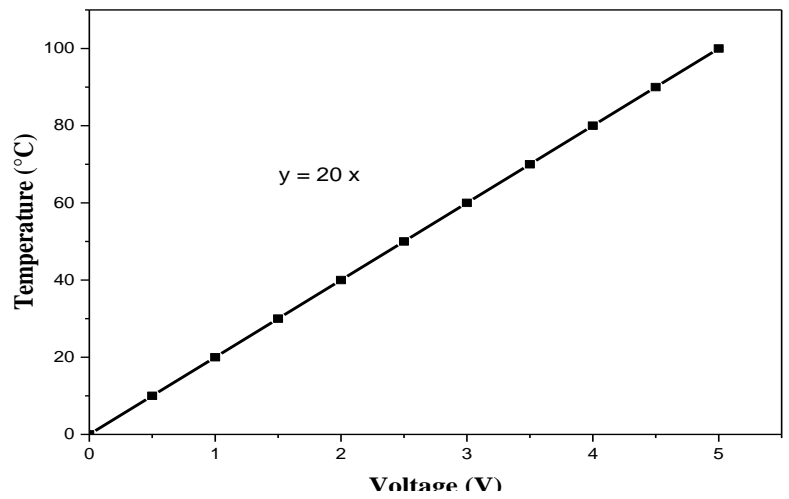

Fig. 6. Temperature characteristic curve

\section{Software system architecture}

The main purpose of this board is to acquire the analog value from the water quality sensors ( $\mathrm{pH}$ and temperature) and transmit them through the SDR module. First, the MCU serial port connected with the MAX6675 and the $\mathrm{pH}$ adaptor circuits are initialized for acquiring the water quality parameters. Then, the microcontroller board converts the signals received from the sensors to $\mathrm{pH}$ and temperature values. If data is not completed, the MCU loop to acquire the sensor parameters. Upon converting data are completed, the MCU sends the information to computer via SDR module which is connected to this controller board. It sends data with a continuous manner. If the transmission data is not completed, it loop to acquire sensors data.

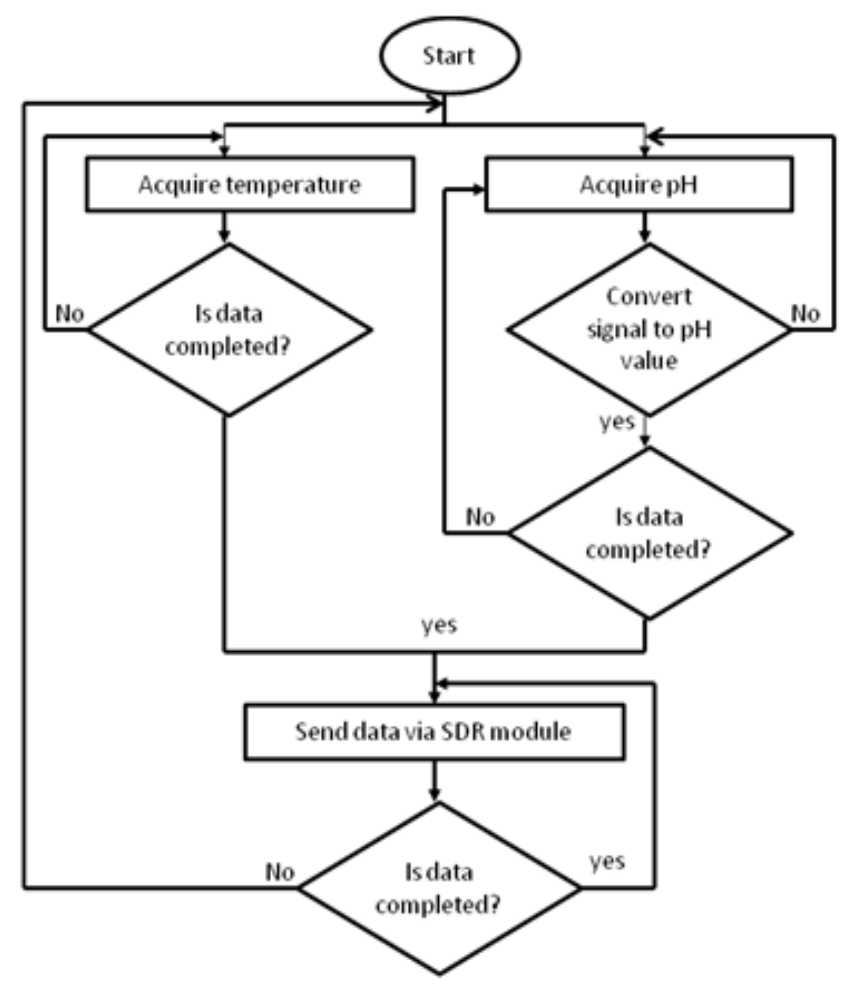

Fig. 7. Software system architecture 


\section{RESULT AND DISCUSSION}

The prototype version developed with the water-quality sensors is shown in Fig. 8. In order to test the prototype system, the $\mathrm{pH}$ and temperature sensors were emerged with another portable $\mathrm{pH}$ and temperature sensors on the same water samples with an accuracy of 0.05 and $0.5^{\circ} \mathrm{C}$ respectively. Thus, it allows the comparison between the data received through SDR module in computer and the direct data measured through the portable sensors. The comparison between the data received and the portable sensors of $\mathrm{pH}$ and temperature are shown respectively in Fig. 9 and 10. After acquiring data from the $\mathrm{pH}$ and temperature sensors, the MCU sends them with a continuous manner to computer. Figure 9 shows the $\mathrm{pH}$ values taking by the sensors system and the portable sensors during 10000 seconds. Except the first values which appear in large difference, the sensors system and portable sensors values difference are negligible as we progress in time axis. The response time of $\mathrm{pH}$ module cause the negligible accuracy difference between the $\mathrm{pH}$ sensors values. Figure 10 shows the temperature values from both the K-type thermocouple sensors which almost coincide with each other except that the sensors system data are deviated in time axis relative to portable sensor data.

The system cost including sensor devices, adaptor modules, MCU board and the SDR module stands at \$270. In real world application, we need a high number of sensor nodes to monitor the water quality parameters on-line in large volume water (rivers, lakes, water distribution system). It is very important to reduce the cost of the sensor nodes which allows reducing the cost of the total system including the bridge USB-UHF, the nanosatellite constellation and the ground station. The system developed in this paper allows defining the delay time taken to transmit sensor data via the microcontroller board.

The best way for increasing the powerful of decision maker related to water management is by combining data between the satellite observations (images, maps...) and the in-situ water quality monitoring system $(\mathrm{pH}$, temperature, conductivity, dissolved oxygen, turbidity...).
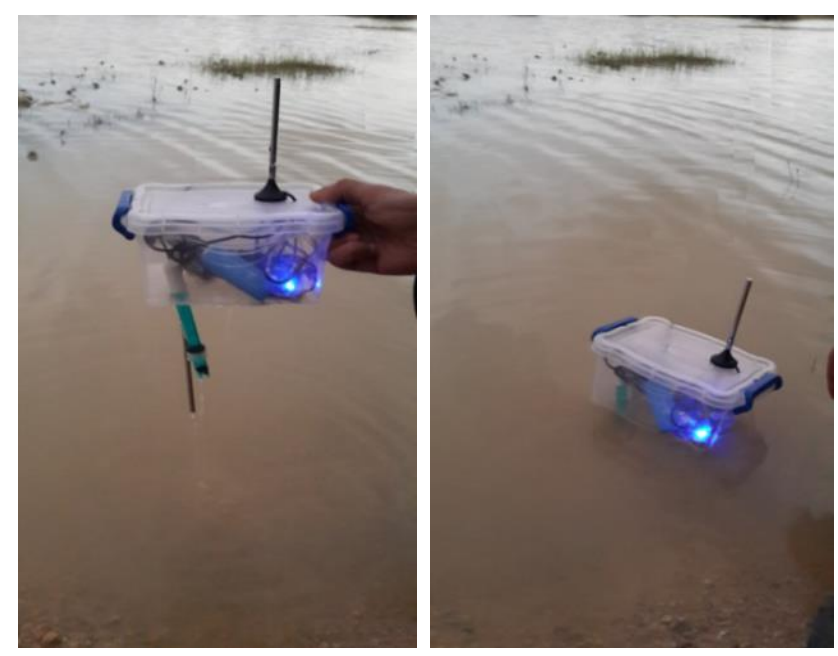

Fig. 8. Prototype of the system with microcontroller board, sensors and SDR module

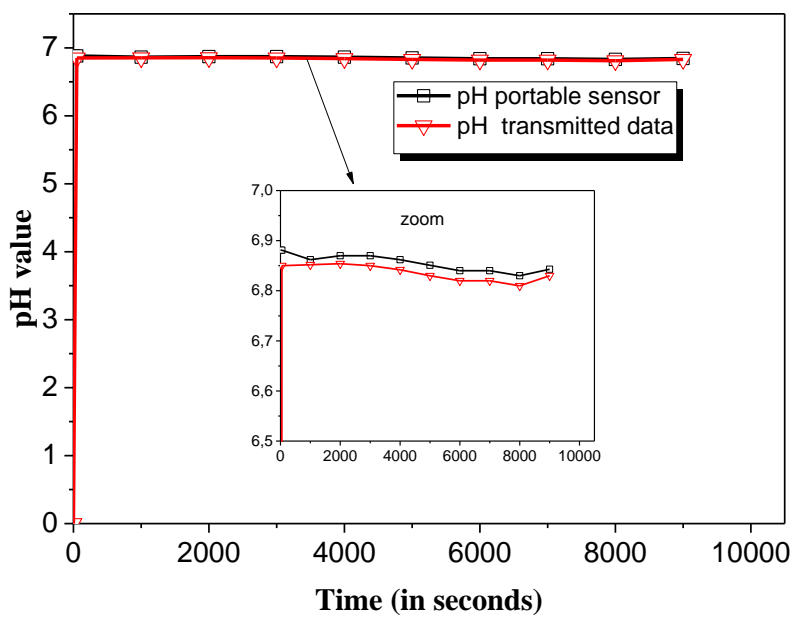

Fig. 9. $\mathrm{pH}$ parameters testing

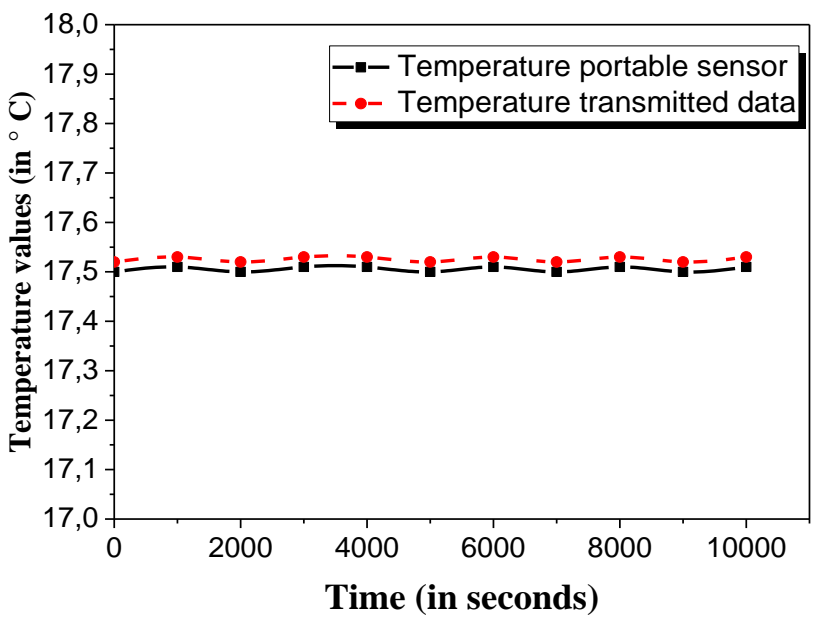

Fig. 10. Temperature parameters testing

Furthermore, an interface of this water quality system based on virtual instrument software was developed (Fig. 11). This interface is simple and clear for all users. It contains a start and exit module used to control the start and stop of monitoring system and graphs for measurement presentation of $\mathrm{pH}$ and temperature. An alarm will be trigger under the conditions discussed below:

- When the $\mathrm{pH}$ value is less than 6.5 or greater than 7.5, an alarm in the form of a red LED triggered to attract the attention of the users,

- When the temperature value exceeds $40^{\circ}$, an alarm in the form of a red LED triggered to attract the attention of the users.

The measured values are stored on specific measurement files, for future processing of data with other analysis software and to be published through browser to provide access to different users. 


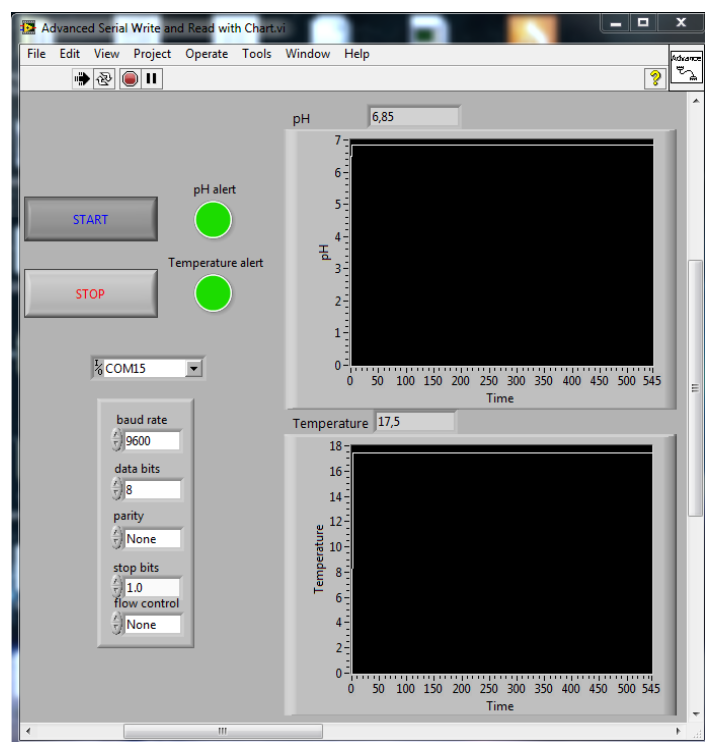

Fig. 11. Sensor measurement interface

\section{CONCLUSIONS}

This paper presented a design of autonomous and in-situ water quality monitoring system based on SDR and small satellite technology. The main objective of this paper is to monitor the surface water quality in real time and remotely. Thus, a low cost system was developed which includes the multi-parameter sensors, acquisition card and the wireless sensor network based on SDR technology. A comparison was set between the results received from the developed system and the direct data measured through portable sensors which are found in a good agreement. In addition, we introduced the small satellite technology for water quality monitoring with new approach for a permanent coverage based on satellite constellation method. Future work will be related to the field of miniaturized water quality sensors.

\section{REFERENCES}

[1] Craun, G. F., Brunkard, J. M., Yoder, J. S., Roberts, V. A., Carpenter, J., Wade, T., ...\& Roy, S. L, "Causes of outbreaks associated with drinking water in the United States from 1971 to 2006", Clinical Microbiology Reviews, Vol. 23, no. 3, pp. 507-528, 2010.

[2] Clark, R. M., Geldreich, E. E., Fox, K. R., Rice, E. W., Johnson, C. H., Goodrich, J. A., ...\& Angulo, F. J, "A waterborne Salmonella typhimurium outbreak in Gideon, Missouri: Results from a field investigation", International Journal of Environmental Health Research, Vol. 6, no. 3, pp.187-193, 1996.

[3] Habib, S., Kfouri, C., \& Peters, M, "Water information system platforms addressing critical societal needs in the MENA region", Geoscience and Remote Sensing Symposium (IGARSS), IEEE International conference, , pp. 2767-2770. July, 2012

[4] Muntadher, A. S., Abdelmalek, T. and Ali, K., "Estimation of Water Quality Parameters Using the Regression Model with Fuzzy K-Means Clustering" International Journal of Advanced Computer Science and Applications(IJACSA), Vol. 5, no. 6, 2014.

[5] Hart, J. K., \& Martinez, K, "Environmental Sensor Networks: A revolution in the earth system science?", Earth-Science Reviews, Vol. 78 no. 3, pp. 177-191, 2006.

[6] Postolache, O. A., Girao, P. M. B. S., Pereira, J. D., \& Ramos, H. M. G, 'Self-organizing maps application in a remote water quality monitoring system", IEEE transactions on instrumentation and measurement, Vol. 54, no. 1, pp. 322-329, 2005.
[7] Toran, F., Ramırez, D., Navarro, A. E., Casans, S., Pelegr1, J., \& Esp1, J. $\mathrm{M}$, "Design of a virtual instrument for water quality monitoring across the Internet", Sensors and Actuators B: Chemical, Vol. 76, no. 1, pp. 281-285, 2005.

[8] Peixeiro, R., Postolache, O., \& Dias Pereira, J. M, "Virtual instrument for water quality parameters measurement", Electrical and Power Engineering (EPE), International Conference and Exposition, , pp. 840844. October 2012.

[9] Stamatescu, G., \& Sgârciu, V, "Integration of wireless sensor networks with virtual instrumentation in a residential environment", arXiv preprint arXiv: 1305.6229, 2013.

[10] Simbeye, D. S., Zhao, J., \& Yang, S, "Design and deployment of wireless sensor networks for aquaculture monitoring and control based on virtual instruments", Computers and Electronics in Agriculture, Vol. 102, pp. 31-42, 2014.

[11] Gómez, C., Aspas, J. P., \& Herrero, J. E. C, "Sensors everywhere: wireless network technologies and solutions", Fundación Vodafone España, 2010.

[12] Ritter, C., Cottingham, M., Leventhal, J., \& Mickelson, A, "Remote delay tolerant water quality montoring", Global Humanitarian Technology Conference (GHTC), IEEE, pp. 462-468. October, 2014.

[13] Du, Z. G., XIAO, D. Q., ZHOU, Y. H., \& OU YANG, G. Z, "Design of water quality monitoring wireless sensor network system based on wireless sensor", Computer Engineering and Design, Vol. 17, 2008.

[14] Zhou, Y., Wen, D., Yuan, F., Li, J., \& Li, M, "Research of Online Water Quality Monitoring System Based on Zibee Network", Advances in Information Sciences \& Service Sciences, Vol. 4, no. 5, pp. 255-261, 2012

[15] Faustine, A., Mvuma, A. N., Mongi, H. J., Gabriel, M. C., Tenge, A. J., \& Kucel, S. B, "Wireless Sensor Networks for Water Quality Monitoring and Control within Lake Victoria Basin: Prototype Development", Wireless Sensor Network, Vol. 6, no. 12,, p. 281, 2014.

[16] Prasanna, G. L., Prasad, S. R., Naidu, C. D., \& Reddy, D. R, "Water Quality Monitoring And Controlling In Irrigation Using Zigbee Technology", International Journal of Science, Engineering and Technology Research, pp. 210-214. January, 2015.

[17] Lonel, R., Vasiu, G., \&Mischie, S, "GPRS based data acquisition and analysis system with mobile phone control. Measurement", Vol. 45, no. 6, pp. 1462-1470. July, 2012.

[18] Xu, D., Li, D., Fei, B., Wang, Y., \& Peng, F, “A GPRS-Based Low Energy Consumption Remote Terminal Unit for Aquaculture Water Quality Monitoring", Computer and Computing Technologies in Agriculture VII, pp. 492-503, 2014.

[19] Li, W., Pan, P., Tan, L. S., \&Luo, X. K, "Remote On-Line Automatic Monitoring System of Reservoir's Water Regimen Based on WSN and GPRS Network", Applied Mechanics and Materials, Vol. 536, pp. 12231230. April, 2014.

[20] Gallah, N., \& Besbes, K, "Small satellite and multi-sensor network for real time control and analysis of lakes surface waters", Recent Advances in Space Technologies (RAST), 6thIEEE International Conference, , pp. 155-158. June, 2013.

[21] Balogh, W, "Capacity building in space technology development: A new initiative within the United Nations programme on space applications", Space Policy, Vol. 27, no. 3, 2011, pp. 180-183. August, 2011.

[22] Leveque, K., Puig-Suari, J., \& Turner, C, "Global Educational Network for Satellite Operations (GENSO)", 2007.

[23] T. Ulversøy, "Software defined radio: challenges and opportunities", IEEE Communications Surveys \& Tutorials, Vol. 12, no. 4, pp. 531-550. 2010.

[24] Lazreg, N., \& Besbes, K, "Design and architecture of Pico-satellites network for earth coverage", Advanced Technologies for Signal and Image Processing (ATSIP), 2nd International Conference on IEEE, , pp. 601-605. March, 2016. 